\title{
África e América do Sul: O futuro passa pela biodiversidade
}

\author{
PAULO ROBERTO FELDMANN ${ }^{I}$
}

\section{Introdução}

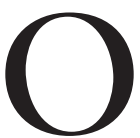

S PAÍSES sul-americanos - especialmente o Brasil - foram os primeiros a serem povoados por imigrantes africanos em todo o continente americano. A imigração africana para as Américas pode ter tido início no século XVI, mas mesmo antes de 1500 os negros já tinham navegado com Cristóvão Colombo em sua primeira viagem em 1492, e é provável que os primeiros exploradores espanhóis e portugueses também tiveram a companhia de negros africanos nascidos e criados na Península Ibérica. Nos 500 anos seguintes, milhões de imigrantes africanos foram trazidos para o Novo Mundo como escravos. Hoje seus descendentes são minorias étnicas expressivas em vários países da América do Sul. Ao longo dos séculos, a população negra contribuiu para a diversidade cultural de suas respectivas sociedades e, dessa forma, influenciaram profundamente todos os aspectos da vida na América do Sul. Mas há outros aspectos importantes que os dois continentes possuem em comum: juntos, África e América do Sul são responsáveis por $50 \%$ da biodiversidade global: aproximadamente 2 milhões de $\mathrm{km}^{2}$ da África são cobertos por florestas tropicais, enquanto a Amazônia, na América do Sul, abrange 6 milhões de $\mathrm{km}^{2}$.

Existe consenso geral de que a América do Sul e a África deveriam conservar melhor e administrar de forma sustentável sua biodiversidade, porém, a fim de alcançar esses objetivos, ambos os continentes devem encontrar maneiras de gerar receitas com a mesma. Vale lembrar que compostos à base de plantas desempenham um papel crucial na síntese de algumas das moléculas mais complexas produzidas pela indústria farmacêutica e, portanto, uma parte importante dos medicamentos atualmente disponíveis provém de produtos naturais como plantas, micro-organismos e animais, direta ou indiretamente.

Biodiversidade é o conjunto de todos os seres vivos existentes ou que já existiram no planeta. A biodiversidade, ou diversidade biológica, lida com todas as variedades de vida na terra (flora, fauna e micro-organismos), ou seja, todas as variações genéticas de populações e espécies, os diferentes impactos ecológicos desses organismos e a enormidade de comunidades, hábitats e ecossistemas formados pelos seres vivos. Estima-se que o número de espécies conhecidas, 
incluindo plantas, animais e micro-organismos, ultrapassa os cinco milhões, mas pelo menos $20 \%$ desse número entrarão em extinção nas próximas décadas.

A biodiversidade é de suma importância por ser responsável por todos os nossos alimentos e grande parte das roupas e dos medicamentos que utilizamos. A destruição da biodiversidade provoca, dentre outros efeitos adversos, o aquecimento global. Para efeitos deste artigo, daremos ênfase ao fato de que a biodiversidade representa uma enorme fonte de informações que podem ser utilizadas pela biotecnologia. Isso diz respeito às aplicações tecnológicas utilizadas por sistemas biológicos ou organismos vivos na fabricação ou alteração de produtos ou processos para fins específicos.

A biotecnologia é o ramo da ciência que pesquisa a transferência de genes de um organismo para outro a fim de dar ao último características do primeiro. $\mathrm{Na}$ verdade, ela é apenas o capítulo mais recente na longa história da produção de alimentos pelo homem. A agricultura organizada teve seus primórdios há cerca de dez mil anos quando os primeiros agrupamentos humanos começaram a se fixar em determinadas áreas e a cultivar lavouras de subsistência. Nesse momento, o homem iniciou seu aprendizado de seleção, reprodução e colheita de sementes, buscando sempre aumentar e melhorar a produção.

\section{Riqueza que poderia ser gerada com a biodiversidade}

Nas antigas civilizações egípcia e grega a fabricação de queijos, cervejas e vinhos já era uma forma primitiva de biotecnologia, baseada em processos de fermentação da uva macerada e cevada, além de outros produtos que eram submetidos à exposição de micro-organismos no ar. Podemos dizer que há séculos, desde que o homem aprendeu a domesticar as plantas e usá-las em benefício próprio, o melhoramento genético vem sendo feito com o objetivo de conseguir plantas mais resistentes e alimentos mais saudáveis. A diferença é que até meados do século XX apenas cruzavam-se espécies de melhor qualidade entre si, o que levava ao melhoramento, mas também levava à transferência das características indesejadas de uma planta para outra. A partir das últimas décadas do século XX com o avanço da biotecnologia e da engenharia genética passou a ser possível transferir para a planta apenas o gene desejado, e isso com muita segurança. Ou seja, agora se tornou possível obter plantas mais saudáveis e alimentos mais abundantes e nutritivos. A modificação genética é uma maneira de inserir genes que conferem às plantas resistência às pragas, fungos e vírus que seriam nocivos ou exigiriam a aplicação de agrotóxicos. Os organismos geneticamente modificados também podem ser resistentes aos pesticidas, o que quer dizer que as ervas daninhas poderão ser facilmente exterminadas. Tudo isso deve elevar muito a produtividade da agricultura e, espera-se, reduzir os preços. No futuro a biotecnologia poderá agregar valor nutricional às safras. Sem dúvida, no século XX foi a química que permitiu os maiores avanços havidos na agricultura e na produção de alimentos. Mas, provavelmente, a química já deu à agricultura tudo o que podia com os fertilizantes, os fungicidas, os inseticidas e os herbicidas. Hoje ela 
custa muito caro em termos de energia e acabou poluindo o solo e as águas. A química agora está sendo substituída pela biotecnologia como o grande fator de avanço na agricultura.

As tentativas de curar as principais doenças que assolam a humanidade datam dos primórdios da civilização, e são facilmente confirmadas quando examinamos registros e dados das primeiras civilizações, entre elas a egípcia, a hebraica, a chinesa e a grega.

No início do século XIX, a morfina pura era extraída das folhas da papoula (Papaver Somniferum). No final desse mesmo século a invenção da aspirina, ou ácido acetilsalicílico, foi resultado direto do conhecimento prévio de que a casca de salgueiro era bastante eficaz para aliviar febre e dores físicas. A descoberta e o isolamento da substância ativa, o ácido salicílico, possibilitaram a fabricação da aspirina.

Um exemplo interessante de informação captada na Floresta Amazônica refere-se ao medicamento conhecido como Captopril, que é indicado para o tratamento de hipertensão e foi patenteado nos Estados Unidos pela Bristol-Myers Squibb. O ingrediente ativo desse medicamento foi descoberto durante estudos sobre o veneno extraído da jararaca, um tipo grande e feroz de cobra brasileira que habita a Floresta Amazônica.

E por que fala-se tanto que a América Latina e a África poderão ter sua grande chance de desenvolvimento por meio da biotecnologia? A resposta se deve ao fato de que a matéria-prima básica da biotecnologia são os genes e o conhecimento que se tem a respeito desses. E por sua vez esses se encontram abrigados, mais do que em qualquer outra parte do planeta, dentro das Florestas Amazônica e Subsaariana. Isso significa que essas florestas têm uma vantagem competitiva inigualável que é a riqueza da suas respectivas biodiversidades.

A indústria farmacêutica é relativamente recente tendo surgido nos Estados Unidos e em alguns países europeus, especialmente a Suíça na metade do século XX. A partir de então, o setor farmacêutico começou a utilizar química sintética para tratar doenças.

Essa época também coincide com o início da interação entre indústrias farmacêuticas e universidades de vários países, que consolidaram as várias etapas necessárias para a descoberta e o desenvolvimento de novos medicamentos.

Assim, as grandes empresas farmacêuticas imediatamente concluíram que precisariam construir grandes laboratórios de pesquisa, empregando milhares de pesquisadores ao redor do mundo.

Hoje, a indústria farmacêutica é o setor que mais investe em pesquisa e desenvolvimento no mundo, e esse valor chega a representar $20 \%$ de suas vendas, enquanto a indústria eletrônica e a indústria automobilística investem $6 \%$ e 5\%, respectivamente.

De acordo com Calixto e Siqueira (2008), um terço dos remédios mais vendidos no mundo foi desenvolvido a partir de produtos naturais. No caso 
daqueles ligados ao tratamento de câncer e antibióticos, essa porcentagem sobe para $70 \%$.

O fato é que a terapia moderna com esses medicamentos não seria possível sem a contribuição de produtos naturais, principalmente as plantas.

\section{A próxima onda tecnológica será a onda da biotecnologia}

Joseph Schumpeter foi um dos economistas mais importantes de todos os tempos e a sua grande contribuição para a Teoria Econômica foi a de relacionar o papel do empreendedorismo e da inovação com o desenvolvimento econômico. Foi um grande defensor da teoria dos ciclos tecnológicos a qual foi concebida inicialmente pelo economista russo Nicolai Kondratiev em 1925. A teoria dos ciclos tecnológicas diz que o crescimento econômico ocorre em ondas, onde cada uma delas tem uma duração aproximada entre 55 e 65 anos. Cada uma dessas ondas está associada a alguma importante mudança tecnológica. Já aconteceram quatro ondas e estamos agora na metade da quinta onda a qual é denominada onda da tecnologia de informação. Kondratiev e Schumpeter diziam que a mudança tecnológica que caracteriza cada onda tem um impacto enorme sobre toda a economia e a sociedade no período da sua vigência. Ao longo dos seus sessenta anos de duração aproximada, cada onda apresenta várias fases que começam com muita euforia e terminam com decadência. Assim sendo, inicialmente a nova onda provoca um grande crescimento econômico e enormes mudanças na sociedade, incluindo quebra de paradigmas e mudanças culturais. A economia mundial passa a depender de forma crescente da nova onda. No entanto, ao final do período a demanda começa a cair, além de haver uma saturação em razão do grande número de empresas que entraram no negócio na fase inicial de sucesso e que acabam competindo fortemente entre si. Nesse momento os investimentos também diminuem, as empresas se concentram em racionalização e o desemprego aumenta. É quando começa a surgir a próxima onda com base no surgimento de alguma nova tecnologia revolucionária. Esse comportamento foi registrado nos últimos 250 anos quando tivemos cinco ondas incluindo a atual, a da tecnologia da informação; as anteriores foram a onda da mecanização, seguida pela onda da força a vapor que terminou em meados do século XIX quando surgiu a onda da eletricidade sucedida no século XX pela onda do automóvel e da produção em massa. A onda atual iniciou-se em meados do século XX e já se encontra em sua etapa final. Para muitos autores a segunda metade do século XXI será dominada pela sexta onda que será a onda da biotecnologia onde predominarão as áreas de medicina, genética, farmacêutica e outras relacionadas.

Dicken (2015), ao analisar os ciclos de Kondratiev, ressalta que em cada uma das fases uma dada mudança tecnológica predominou e permitiu que algumas nações crescessem bem mais que outras. Concluindo assim que só esse fator já seria suficiente para que a questão geográfica fosse mais bem compreendida no sentido de se tentar entender como surgem as inovações tecnológicas. Dicken 
enfatiza a questão do porquê as inovações tecnológicas serem muito frequentes em algumas regiões e escasseiam ou não existem em outros espaços geográficos. Segundo ele existe uma relação direta entre condições geográficas e surgimento de inovações tecnológicas. Nessa linha, a nossa visão é de que justamente na próxima onda, a onda da biotecnologia ou das ciências da vida, tanto a América do Sul como a África terão finalmente a sua grande oportunidade de se desenvolver graças ao conhecimento embutido na enorme biodiversidade que sediam.

\section{Importância da biodiversidade para o desenvolvimento das duas regiões}

Setecentos e cinquenta milhões de pessoas vivem com menos de um dólar por dia em áreas rurais e frequentemente dependem de uma ampla variedade de recursos naturais e serviços ecossistêmicos para seu bem-estar. Portanto, elas se tornam mais vulneráveis quando a diversidade é degradada ou destruída. Grande parte da população pobre do mundo vive na América do Sul e na África.

Em razão da Amazônia, a América do Sul é a região do planeta que contém o maior número de espécies conhecidas no planeta. Nesse aspecto, o Brasil é o país mais importante do continente. A África ocupa a segunda posição em termos de biodiversidade.

Ela abriga uma biodiversidade incrivelmente diversa e rica, que fornece serviços ecossistêmicos essenciais, com potencial para impulsionar a economia do continente. Seus organismos vivos constituem-se aproximadamente num quarto da diversidade global e incluem o maior conjunto intacto de grandes mamíferos da terra, que vivem livremente em muitos de seus países. Porém, estima-se que até 2100 a mudança climática poderá provocar a extinção de mais da metade das espécies de pássaros e mamíferos da África e uma grande parcela das espécies de plantas.

A abundante biodiversidade da Amazônia confere a ela uma vantagem competitiva imbatível. A variedade de espécies de animais e plantas que existem no ecossistema da Amazônia representa o maior arquivo biológico conhecido de genes, moléculas e micro-organismos. Isso significa que a biodiversidade da Amazônia é a chave para o desenvolvimento de diversos produtos, como medicamentos, alimentos, fertilizantes, pesticidas, plásticos, solventes, cosméticos, tecidos e fermentos. A Floresta Amazônica abrange nove países - Bolívia, Brasil, Colômbia, Equador, Guiana Francesa, Guiana, Peru, Suriname e Venezuela - e possui aproximadamente $26 \%$ do material genético do planeta, ou seja, $26 \%$ de todas as sequências de DNA combinadas na natureza.

De um ponto de vista ético, a indústria farmacêutica vem sendo criticada por obter sua matéria-prima mediante pesquisas das regiões mais pobres do mundo - embora seus medicamentos sejam utilizados predominantemente nos países mais desenvolvidos - e por quase nada ser feito para combater as doenças tropicais.

Isso é motivo suficiente para a América do Sul e a África prestarem mais atenção na biotecnologia, apesar de os objetivos dos países mais avançados em 
relação aos resultados dos estudos de biotecnologia divergirem bastante dos objetivos e das necessidades dos países dos continentes pobres. Muitos autores, como Silveira et al. (2005), consideram que as aplicações no setor agrícola seriam importantíssimas para reduzir os custos na indústria alimentícia, aumentar a produção ou desenvolver o setor rural. Nos países mais desenvolvidos, esses aspectos raramente são prioridade. Suas prioridades são a produção de medicamentos para atender demandas específicas, como aquelas relacionadas ao câncer ou à produção de insulina humana. Em outras palavras, podemos dizer que os países mais desenvolvidos priorizam o aspecto farmacêutico e de assistência médica da biotecnologia. Mesmo assim, eles não possuem referência sobre as questões que afligem a América do Sul e a África. Nesses continentes, em termos de assistência médica, a biotecnologia pode ser vital para diagnósticos, vacinas e prevenção contra doenças transmissíveis nos trópicos, que geralmente afetam as classes mais baixas de suas populações.

Muitos cientistas concordam com a tese de Lovejoy (2006) de que a África e a América do Sul, tendo controle de quase metade da biodiversidade mundial, deveriam investir para aproveitar essa herança natural em prol da economia de seus países.

Descobertas e pesquisas biomédicas, bem como o desenvolvimento de medicamentos frequentemente buscam utilizar materiais naturais em produtos e aplicações. Bioprospecção é o nome desse processo bastante utilizado pelas empresas farmacêuticas. Portanto, muitos medicamentos em potencial provêm do ambiente biodiverso e do conhecimento de nativos de países em desenvolvimento. É exatamente isso que acontece em ambas as regiões, onde nenhum país - nem na América do Sul nem na África -, em razão dos elevados custos de parques tecnológicos, consegue competir no mercado de medicamentos sintéticos. Não há nenhum país sul-americano ou africano atuante na indústria farmacêutica e, se observarmos os nomes das $\mathbf{5 0}$ maiores empresas do mundo nesse setor, não encontraremos nenhuma dessas regiões. Isso se deve porque o desenvolvimento de um medicamento sintético demanda investimentos muito altos em pesquisa e desenvolvimento, algo que acaba não sendo viável para os laboratórios farmacêuticos africanos e sul-americanos. Estima-se que entre $40 \%$ e $50 \%$ dos medicamentos disponíveis no mundo foram desenvolvidos a partir de produtos naturais provenientes de pesquisas realizadas na natureza. É nesse ponto que a biodiversidade da América do Sul e da África poderia reduzir as respectivas despesas de seus países com saúde. É essencial para esses continentes estabelecer políticas que as favoreçam em casos em que os principais ingredientes ativos dos medicamentos são derivados de plantas, micro-organismos ou mesmo animais que fazem parte de seu hábitat.

\section{A biopirataria prejudica tanto a América do Sul quanto a África}

A bioprospecção vem sendo amplamente utilizada pelos laboratórios farmacêuticos na obtenção dos ingredientes ativos necessários para produzirem 
seus medicamentos. No entanto, a bioprospecção quase nunca resulta em benefício para as comunidades em que as plantas são descobertas ou o conhecimento necessário para a produção dos ingredientes ativos é obtido. Isso é a biopirataria.

De forma simplificada, entende-se por biopirataria a utilização de recursos naturais e conhecimento tradicional sem autorização governamental prévia para tanto. $\mathrm{O}$ tráfico de animais, a extração de ingredientes ativos de plantas e a utilização do conhecimento de povos indígenas sem autorização prévia são exemplos de biopirataria.

Em razão de sua grande biodiversidade, a África e a América do Sul normalmente são vítimas da biopirataria. Essa prática também aumentou com o avanço da biotecnologia, pois o transporte de recursos genéticos, por exemplo, é mais fácil e rápido que o transporte de animais ou plantas.

Becker (2006) descreve a biopirataria como pesquisadores disfarçados de turistas ou estudantes que vão para a África ou a América do Sul a fim de coletar elementos de sua biodiversidade. Às vezes eles se passam por representantes de Organizações Não Governamentais (ONG) ou por missionários religiosos. Também existem os contrabandistas que chegam à região com um único objetivo: roubar recursos naturais para a produção de novos produtos, que podem ser medicamentos - os mais comuns -, alimentos, maquiagens ou produtos agrícolas.

Em resumo, biopirataria é o roubo de materiais biológicos, tais como genes, sementes e plantas. Algumas importantes multinacionais farmacêuticas obtêm lucros enormes com a biodiversidade da África e da América do Sul, mas não partilham esses lucros com as comunidades que descobrem e transmitem o conhecimento.

\section{O impacto do protocolo de Nagoya em ambas as regiões}

Após um intenso debate que durou quase duas décadas, a ECO 92, Conferência das Nações Unidas sobre o Meio Ambiente realizada em 1992 no Rio de Janeiro, lançou a Convenção sobre Diversidade Biológica (CBD). A CBD é uma convenção internacional que visa conservar a biodiversidade e promover seu uso sustentável, bem como repartir de forma justa e igualitária seus benefícios. Foi acordado durante essa convenção que os países são soberanos sobre os recursos genéticos encontrados em seus territórios, e estabeleceu-se o direito aos benefícios pelo uso de sua biodiversidade.

Cento e noventa e quatro países assinaram a convenção. A fim de implementar diretrizes e estabelecer regras e sanções operacionais, foi criado e aprovado durante uma conferência da CBD em 2010, no Japão, um Protocolo sobre Acesso a Recursos Genéticos e Repartição de Benefícios, conhecido como Protocolo de Nagoya.

De acordo com a CBD, o "Protocolo de Nagoya sobre Acesso a Recursos Genéticos e Repartição Justa e Equitativa dos Benefícios Derivados de sua Utilização para a Convenção sobre Diversidade Biológica" é um acordo internacional que visa repartir os benefícios derivados da utilização dos recursos genéticos 
de forma justa e igualitária. Ele foi celebrado em 12 de outubro de 2014, noventa dias após a data de depósito do quinquagésimo instrumento de ratificação.

O Protocolo de Nagoya gerou maior segurança jurídica e transparência para fornecedores e aqueles que utilizam recursos genéticos:

- Estabelecendo condições mais previsíveis de acesso aos recursos genéticos.

- Ajudando a garantir a repartição de benefícios quando os recursos genéticos deixarem seu país fornecedor.

Ao ajudar a garantir a repartição de benefícios, o Protocolo de Nagoya cria incentivos para a conservação e a utilização sustentável dos recursos genéticos, melhorando assim a contribuição da biodiversidade para o desenvolvimento e o bem estar da humanidade.

O principal objetivo do Protocolo de Nagoya foi criar um sistema internacional de repartição de benefícios entre os países signatários. Dessa forma, os benefícios gerados em qualquer nação deveriam ser encaminhados ao país de origem dos recursos genéticos naturais. Antes do Protocolo de Nagoya, os países de origem desses recursos não dispunham de mecanismos para obter os benefícios derivados do produto final comercializado em outro país. Como resultado do Protocolo de Nagoya, é possível estarmos testemunhando o surgimento de uma nova era, onde países pobres finalmente podem obter vantagens com sua biodiversidade.

\section{Obtenção de vantagem competitiva por países pobres, porém ricos em biodiversidade}

Conforme mencionado por Sofia Faruqui (2007) em seu artigo na SSIR Stanford Social Innovation Review, "mais empresas precisam compreender os efeitos positivos da biodiversidade sobre seus resultados líquidos - e mais governos precisam aprovar leis que protejam a biodiversidade...". Faruqui também mencionou que o turismo, de forma geral, é a segunda fonte de renda dos países da América do Sul e da África devido às grandes áreas relacionadas à biodiversidade e ao ecoturismo, que geraram US\$ 77 bilhões para ambas as regiões em 2016. Entretanto, esse valor é muito baixo quando comparado aos lucros obtidos por vários outros setores que utilizam o conhecimento da biodiversidade. A indústria farmacêutica, por exemplo, teve uma renda global de US\$ 1,3 trilhão em 2017. É muito difícil estimar quanto desse volume deriva do conhecimento da biodiversidade, mas o valor com certeza é bastante significativo. O mesmo ocorre com os fabricantes de pesticidas, cujos ganhos somaram mundialmente US\$ 52 bilhões no mesmo ano.

No início do século XXI, o surgimento de novas tecnologias químicas combinatórias e de triagem molecular de alta velocidade nas indústrias farmacêuticas indicou o fim da biodiversidade como uma importante fonte de conhecimento. Entretanto, após utilizar essas novas tecnologias por aproximadamente quinze anos, laboratórios e setores farmacêuticos concluíram que a biodiversida- 
de continua sendo vital. Eles entenderam que a aplicação do conhecimento de produtos naturais junto com as tecnologias químicas combinatórias é o caminho para a descoberta de novos medicamentos. Os produtos naturais estão sendo utilizados como modelos para a química combinatória em razão de sua estrutura especial. Como resultado disso, hoje é possível criar grande número de moléculas análogas que permitiriam descobrir de forma mais rápida o princípio ativo de medicamentos. Essa é uma ótima notícia para os países ricos em biodiversidade, principalmente após a assinatura do Protocolo de Nagoya.

Porém, os países sul-americanos e africanos ainda têm muitos desafios pela frente antes de começarem a lucrar com sua biodiversidade. Antes de tudo, é necessário que esses dois continentes juntem forças para que possam trocar experiências e, especialmente, definir mecanismos consoantes com o Protocolo de Nagoya a fim de obter lucros reais. Para tanto, existem alguns dados operacionais e práticos que devem ser estabelecidos:

- Quanto cobrar das empresas farmacêuticas nos países produtores e de que forma tal cobrança deve ser realizada.

- Qual metodologia ou processo deve ser utilizado para que as grandes empresas farmacêuticas e de pesticidas transmitam sua tecnologia para as empresas africanas e sul-americanas desses mesmos setores. Isso terá oposição das empresas farmacêuticas no início, mas esse é um dos aspectos mais importantes a serem negociados.

- Implementação de um processo de intercâmbio entre universidades importantes na área de biotecnologia de países em desenvolvimento e universidades da África e da América do Sul a fim de treinar professores para essas regiões.

- Desenvolvimento de recursos humanos e criação de infraestrutura na África e na América do Sul para tornar essas regiões competidoras importantes na produção de medicamentos, pesticidas, cosméticos, alimentos e outros produtos agrícolas. A cooperação entre os países dessas regiões é um fator fundamental para atingir esse objetivo.

- Criação de um fórum para discutir e definir mecanismos de troca de informações entre os dois continentes para que haja um desempenho coletivo na defesa, proteção e preservação da biodiversidade e, principalmente, na obtenção de resultados econômicos dela derivados.

- Incentivo à criação de pequenas empresas voltadas à exploração da biodiversidade para encontrar novos conhecimentos a partir de plantas, micro-organismos e animais e que poderiam ser vendidos para empresas farmacêuticas.

- O financiamento de todas essas atividades e processos é um grande desafio para os países dessas duas regiões e será necessário o envolvimento das mais importantes instituições internacionais, como o Banco Mundial, a FAO (Organização das Nações Unidas para Alimentação e Agricultura) e outras. 


\section{Considerações finais}

A América do Sul e a África enfrentam alguns problemas em comum: Ambos continentes têm uma competitividade muito baixa e precisam combater e reduzir a pobreza e a fome. Várias estratégias diferentes foram utilizadas para resolver esses problemas, mas em nenhuma delas foi considerado utilizar como vantagem competitiva uma importante fonte de riqueza disponível em ambas regiões: a biodiversidade.

Tentamos demonstrar que, sem o conhecimento da biodiversidade, não é possível o desenvolvimento de medicamentos, pesticidas, cosméticos e muitos outros produtos. Mesmo com os avanços das tecnologias químicas combinatórias e de triagem molecular de alta velocidade, a biodiversidade continua sendo uma fonte vital de informações. Não é justo que as nações que abrigam tal biodiversidade não possam se beneficiar disso. Essa riqueza deve ser transformada em negócios que garantirão o desenvolvimento econômico e social desses países.

É interessante notar que um dos maiores erros cometidos no passado pelos países africanos e sul-americanos foi ter como base de seu desenvolvimento os vastos recursos naturais de suas regiões. No entanto, por mais contraditório que pareça, é no começo do século XXI que uma enorme janela de oportunidades se abre para boa parte dos países da África e da América do Sul, exatamente por causa de seus recursos naturais. Boa parte do conhecimento que será importante para aprimorar esses novos temas está presente no conhecimento que podemos extrair da flora e da fauna dos dois continentes. A África e a América do Sul nunca foram atores importantes no cenário econômico internacional, mas essas duas regiões jamais tiveram uma oportunidade como essa.

Em suma, esperamos ter demonstrado a existência de muitas possibilidades de medidas e de políticas públicas que deveriam ser consideradas por especialistas de ambas as regiões para que se promova negócios e comércio que poderiam derivar da biodiversidade. Além disso África e América do Sul deveriam trabalhar conjuntamente incentivando discussões e estabelecendo medidas, o que também contribuirá para a criação de oportunidades comerciais a partir de suas respectivas biodiversidades. As indústrias de pesticidas, cosméticos, farmacêutica e alimentícia que quase sempre estão concentradas nos países mais desenvolvidos tiveram grandes benefícios com o conhecimento decorrente da biodiversidade, mas isso não ocorre nas regiões que possuem essa biodiversidade, que em sua maioria são de países pobres. Algumas importantes multinacionais farmacêuticas obtêm lucros enormes com a biodiversidade da África e da América do Sul, mas não partilham esses lucros com as comunidades que detêm, descobrem e transmitem o conhecimento. Em outras palavras, podemos dizer que os países mais desenvolvidos priorizam o aspecto farmacêutico e de assistência médica da biotecnologia. Mesmo assim, eles não possuem referência sobre as questões que afligem a América do Sul e a África. Nas ondas tecnológicas anteriores esses dois continentes não conseguiram um papel de protagonistas, mas dessa vez eles 
possuem a riqueza da biodiversidade que certamente será um fator fundamental para que ambos passem a ter um papel mais ativo e com isso poderão resolver seus graves problemas de estagnação e pobreza.

\section{Referências}

ALENCAR, A. F. de. A proteção dos conbecimentos tradicionais associados ao patrimônio genético da Amazônia Brasileira. Manaus: Plataforma Pública Direito. 2010.

ANDERSON-SPRECHER, A.; JIE, M. China considering major revisions on Biotechnology Regulations. Global Agricultural Information Network, 2015. GAIN report 14032 de $31 / 12 / 2014$.

BECKER, B. K. Da preservação à utilização consciente da biodiversidade Amazônica. Petrópolis: Vozes, 2006.

CALIXTO, J. B.; SIQUEIRA, J. M. Desenvolvimento de medicamentos no Brasil: Desafios (The drug development in Brazil: Challenges). Gazeta Médica da Babia, v.78, p.98-106, 2008.

CARRER, H.; BARBOSA, A. L.; RAMIRO, D. A. Biotecnologia na Agricultura. Revista de Estudos Avançados, v.24, n.70, 2010.

CDB - CONVENTION ON BIOLOGICAL DIVERSITY. Nagoya Protocol on Access to Genetic Resources and Fair and Equitable Sharing of Benefits Arising from their utilization on the Convention on Biological Diversity. Montreal, Canada. United Nations: Secretariat of Convention on Biological Diversity. 2011.

DICKEN, P. Global Shift: Mapping the changing contours of the world economy. 7 ed. London: Guilford Publications. 2015

FALEIRO, F. G. et al. Biotecnologia: estado da arte e aplicações na agropecuária. Brasília: Embrapa, 2011.

FAO - Food and Agriculture Organization of the United Nations. The state of food security and nutrition in the world. Roma: FAO, 2017.

FARUQI, S. The business of Biodiversity. SSIR - Stanford Social Innovation Review, v.15, n.1, 2017.

FELDMANN, M. G.; SILVA, M. N. C. Currículo Relacional na Amazônia. Revista e-Curriculum, v.16, n.4, 2018.

FELDMANN, P. R. Management in Latin America: Threats and Opportunities in the Globalized World. New York: Springer, 2014.

KONDRATIEV, N. The long wave in economic life. Review of Economic Statistics, v.17, p.105- 15, 1925.

LOVEJOY, T. E. Climate Change and biodiversity. The energy and resources institute. Michigan: Yale University Press, 2006.

PACANARO, R. F. Biopirataria: falta de legislação específica. Piracicaba, 2010. Dissertação (Mestrado) - Unive4rsidade Metodista de Piracicaba.

PIMENTEL, V. et al. Biodiversidade brasileira como fonte da inovação farmacêutica: uma nova esperança? Revista do BNDES, n.43, p.41-9, jun. 2015. 
RABITZ, F. Biopiracy after the Nagoya Protocol: Problem Structure, Regime Design and Implementation Challenges. Revista da Associação Brasileira de Ciência Politica, v.19, n.2, p.30-53, 2015.

RIFKIN, J. O século da biotecnologia. São Paulo: Makron Books, 1999.

SCHUMPETER, J. Capitalism, socialism and democracy. London: Allen\& Unwin, 1943.

SILVEIRA, J. M. F. J. et al. Biotecnologia e agricultura: da ciência e tecnologia aos impactos da inovação. São Paulo em Perspectiva, v.19, n.2, 2005.

WILSON, E. O. The creation: an appeal to save life on earth. New York: W.W. Norton, 2006.

RESUMO - Este artigo tem como objetivo mostrar que a África e a América do Sul poderiam se beneficiar muito mais dos recursos que possuem em suas florestas tropicais. Isso ocorre porque a biodiversidade fortemente presente nos dois continentes é a base para o desenvolvimento de muitos medicamentos, pesticidas e outros produtos produzidos pela indústria química e farmacêutica, mas essas estão localizadas nas regiões mais desenvolvidas do planeta. O artigo lista os autores que abordaram a questão e propõem medidas que podem transformar esses continentes mais pobres de meros fornecedores de conhecimento de plantas em importantes fabricantes farmacêuticos. Discute-se que a biotecnologia será uma das disciplinas mais importantes em menos de trinta anos e ela precisa do conhecimento existente nas plantas e por isso a importância da biodiversidade. Também é discutido que a biopirataria prejudica ambas as regiões, mas felizmente e devido ao recente Protocolo de Nagoya, existem novas ferramentas para eliminar esse enorme problema.

PALAVRAS-CHAVE: Biodiversidade, América do Sul, África, Biotecnologia, Protocolo de Nagoya.

ABSTRACT - This article aims to show that Africa and South America could benefit more from the resources of their tropical forests. This is because the biodiversity strongly present on both continents is the basis for the development of many drugs, pesticides, and other products of the chemical and pharmaceutical industry, which, however, are located mainly in the most developed regions of the planet. The article lists the authors who have addressed this issue and proposes measures that could transform these poorer continents from mere suppliers of plant-based knowledge into important pharmaceutical manufacturers. It claims that biotechnology will be one of the most important disciplines less than thirty years from now, but depends on the knowledge found in the plants, which is the reason why biodiversity is so important. And it also discusses how biopiracy harms both regions, although because of the recent Nagoya Protocol, there are fortunately new tools to eliminate this huge problem.

KEYWORDS: Biodiversity, South America, Africa, Biotechnology, Nagoya Protocol.

Paulo Roberto Feldmann é professor associado livre-docente da Faculdade de Economia, Administração, Contabilidade e Atuária desde 1981. Engenheiro pela Poli-USP com mestrado e doutorado feitos na Fundação Getúlio Vargas. É também professor visitante 
de quatro universidades húngaras (Pécs, Corvinus, Széchenyi e Miskolc) e membro da Academia de Ciências da Hungria. Trabalhou na Amazônia como diretor de planejamento do Grupo Sharp.

@ - feldmann@usp.br / https://orcid.org/0000-0001-5662-8735.

Recebido em $1^{\circ} .10 .2019$ e aceito em 2.1.2020.

${ }^{\text {I }}$ Universidade de São Paulo, Faculdade de Economia, Administração, Contabilidade e Atuária, São Paulo, Brasil. 
